\title{
FURTHER RESULTS ABOUT NORMAL CRITERIA AND SHARED VALUES FOR FAMILIES OF MEROMORPHIC FUNCTIONS
}

\author{
JIANMING QI
}

\begin{abstract}
Let $k$ be a positive integer and let $\mathscr{F}$ be a family of meromorphic functions in the domain D all of whose zeros with multiplicity at least $k$. Let $P$ be a polynomial and $P$ have at least one simple zero, $p=\operatorname{deg}(P) \geqslant k+2$. If, for each pair $f, g \in \mathscr{F}, P(f) G^{m}(f)$ and $P(g) G^{m}(g)$ share a nonzero constant $b$ ignoring multiplicity in D, where $G(f)=P\left(f^{(k)}\right)+$ $H(f)$ is a differential polynomial of $f$ satisfying $\left.\frac{w}{\operatorname{deg}}\right|_{H} \leqslant \frac{k m q}{l+m q}+1$ or $w(H)-\operatorname{deg}(H)<q k$, and $q>l \geqslant k+1$ is a positive integer, then $\mathscr{F}$ is normal in $\mathrm{D}$.
\end{abstract}

Mathematics subject classification (2010): 30D35, 30D45.

Keywords and phrases: Normal family, Nevanlinna theory, sharing values, meromorphic function.

Acknowledgement. This work was supported by Applied Mathematical Academic Discipline Project of Shanghai Dianji University(16JCXK02), and Humanity and Social Science Youth foundation of Ministry of Education(18YJC630120).

\section{REFERENCES}

[1] W. BergweiLer, Bloch's principle, Comput Methods Funct. Theory., 6, (2006), 77-108.

[2] W. Bergheiler and A. Eremenko, Complex dynamics and value distribution, In Intenational Conference of Complex Analysis, Nanjing, 1994.

[3] M. ChaO, Normal families and shared values of meromorphic functions, Bull. Malays. Math. Sci. Soc., 2, 31(2008), 1 85-90.

[4] H. H. Chen AND Y. X. Gu, Improvement of Maty's criterion and its application, Sci China. Ser A, 36(1993) 647-681.

[5] H. H. Chen AND M. L. FAng, On the value distribution of $f^{n} f^{\prime}$, Sci China. Ser A, 38(1995), 789798.

[6] J. Clunie, On a result of Hayman, J. London Math Soc. 42(1967), 389-392.

[7] M. L. Fang And L. Zalcman, A note on normality and shared values, J. Aust. Math. Soc., 76(2004), 141-150.

[8] Y. X. GU, On normal families of meromorphic functions, Sci China. Ser A, 36(1978), 373-384.

[9] W. K. Hayman, Meromorphic functions, Clarendon Press, Oxford, 1964.

[10] W. K. Hayman, Picard value of meromorphic functions and their derivatives, Ann. of Math. 70(1959), 9-42.

[11] W. K. HaYman, Research problem in function theory, Athlone Press, University of London, 1967.

[12] P. C. HU AND D. W. Meng, Normality criteria of meromorphic functions with multiple zeros, J. Math. Anal. Appl., 357(2009), 323-329.

[13] C. L. LEI AND M. L. FANG, Normality and shared values concerning differential polynomials, Sci China. Ser A., 53(2010), 749-754.

[14] L. C. LeI, M. L. FAnG AND D. G. YANG, Normal families and shared values of meromorphic functions, Proc. Japan Acad.(Ser. A), 83(2007), 36-39.

[15] S. Y. Li AND H. C. XIE, On normal families of meromorphic functions, Acta Math. Sinica, 29(1986), 468-476. 
[16] Y. T. Li And Y. X. Gu, On normal families of meromorphic functions, J. Math. Anal. Appl, 354(2009), 421-425.

[17] E. Mues, Über ein Problem von Hayman, Math. Z. 164(1979), 239-259.

[18] I. B. OsHKIN, On a test for the normality of families of holomorphic functions, Uspekhi Mat. Nauk, 37(2)(1982), 221-222.

[19] X. C. PANG, Bloch principle and normal criterion, Sci China Ser A, 32(1989), 782-791.

[20] X. C. PAng And L. Zalcman, Normal families and shared values, Acta Math. 76(2000), 171-182.

[21] X. C. Pang And L. Zalcman, Normal families and shared values, Bull London Math Soc. 32(2000), 325-331.

[22] J. M. QI, J. Ding AND L. Z. Yang, Normality Criteria for Families of Meromorphic Function Concerning Shared Values, Bull. Malays. Math. Sci. Soc. 2, 35 (2012), 449-457.

[23] J. Schiff, Normal Families, Springer-Verlag, Berlin, 1993.

[24] W. SCHWICK, Sharing values and normality, Arch. Math. 59(1992), 50-54.

[25] J. Y. Xia AND Y. XU, Normality criterion concerning sharing functions, Bull. Malays. Math. Sci. Soc. 2, 33(2010), 479-486.

[26] J. F. XU AND W. S. CAO, Some normality criteria of meromorphic functions, J.,Inequ., Appl., 2010, articles ID 926302, 10 pages, doi:10.1155/2010/926302.

[27] C. C. Yang AND H. X. YI, Uniqueness Theory of Meromorphic Functions, Kluwer Academic Publishers 2003.

[28] C. C. YAng And P. C. Hu, On the value distribution of $f f^{(k)}$, Kodai Mathematical Journal, 2, 19(1996), 157-167.

[29] L. YANG, Value distribution theory, Springer-Verlag, Berlin, 1993.

[30] L. YANG AND G. H. ZhANG, Recherches sur la normalité des familles de fonction analytiques à des valeurs multiples, I. Un nouveau critère et quelques applications, Sci China. Ser A, 14(1965), 1258-1271; II. Généralizations, Ibid. 15(1966), 433-453.

[31] L. Zalcman, Normal families New perspectives, Bull. Amer. Math. Soc. 35(1998), 215-230.

[32] Q. C. ZhANG, On normal criterion of holomorphic functions, Math. Practice and Theory. 36(2006), 283-286.

[33] Q. C. Zhang, Some normality criteria of meromorphic functions, Complex Var. Elliptic Equ. 53(2008), 791-795.

[34] Z. L. Zhang And W. Li, Picard exceptional values for two class differential polynomials, Acta. Math. Sinica. 34(1994), 828-835. 